\title{
DNA-Binding Protein Ikaros
}

National Cancer Institute

\section{Source}

National Cancer Institute. DNA-Binding Protein Ikaros. NCI Thesaurus. Code C68732.

DNA-binding protein Ikaros (519 aa, $58 \mathrm{kDa}$ ) is encoded by the human IKZF1 gene. This protein is a transcriptional enhancer that is involved in B- and T-cell maturation. 